\title{
DESAIN M-LEARNING POLITEKNIK MANUFAKTUR BANGKA BELITUNG
}

Riki Afriansyah" ${ }^{1)}$, M Setya Pratama ${ }^{2}$

${ }^{1}$ Teknik Elektro dan Informatika, Politeknik Manufaktur Bangka Belitung

${ }^{2}$ Teknik Mesin, Politeknik Manufaktur Bangka Belitung

E-mail: riki.afrian@gmail.com

\begin{abstract}
Abstrak - Perkembangan internet dan mobile menjadi sebuah kemudahan bagi para dosen dan mahasiswa dalam melakukan proses kegiatan belajar mengajar. Penerapan m-learning sangatlah penting bagi mahasiswa untuk belajar dan mendapatkan bahan ajar yang diberikan oleh dosen. Metode gaya belajar VAR (Visual, Audio, Read) memiliki peranan penting dalam kemudahan mahasiswa untuk memahami gaya belajar yang disukainya agar bahan ajar yang diberikan dapat dengan mudah dipahami. Politeknik Manufaktur Bangka Belitung (Polman Babel) sendiri belum menerapkan sistem e-learning. Diharapakan dengan penelitian desain m-learning Polman Babel ini dapat mempermudah mahasiswa untuk mendapatkan bahan ajar perkuliahan serta ujian online berbasis mobile. Dalam mendesain $m$ learning ini menggunakan model ADDIE serta melakukan evaluasi terhadap hasil desain m-learning yang telah dibangun. Hasil survei yang dilakukan dihubungkan dengan model TAM. Hasil evaluasi dari 44 responden diperoleh persepsi kemudahan penggunaan 82,14\%, persepsi manfaat $82,06 \%$ dan minat perilaku menggunakan teknologi 80,62\%. Serta mahasiswa Polman Babel lebih menyukai gaya belajar visual dengan persentase $84,09 \%, 6,82 \%$ audio dan $9,09 \%$ read
\end{abstract}

Kata Kunci: m-learning, bahan ajar, VAR, ADDIE, model TAM

\section{PENDAHULUAN}

Perkembangan teknologi yang semakin pesat menjadi sebuah kebutuhan bagi institusi pendidikan untuk mempermudah dalam proses pembelajaran. Pengunaan perangkat mobile dan teknologi nirkabel memungkinkan dalam pencapaian proses pembelajaran yang lebih optimal[3]. M-learning merupakan sebuah model pembelajaran berbasis teknologi untuk mempermudah mahasiswa mengakses materi pembelajaran dengan memanfaatkan perangkat mobile. M-learning dapat menjadi salah satu teknologi pedagogi yang menjanjikan untuk digunakan dalam lingkungan pendidikan yang lebih tinggi[5].

Penerapan m-learning belum pernah diterapkan di Politeknik Manufaktur Negeri (Polman) Bangka Belitung sehingga mahasiswa sangat sulit untuk mendapatkan materi pembelajaran yang ada. Dalam pengadopsian $m$ learning ada tiga kategori faktor yang mempengaruhi yaitu: fitur dalam perangkat, harapan pengguna dan keunggulan pedagogi[3]. Setiap mahasiswa memiliki gaya belajar yang berbeda-beda dalam memahami materi pembelajaran. Penerapan gaya belajar dalam pembelajaran mempunyai dampak pada performansi e-learning[4]. Oleh karena itu fitur dan konten yang tersedia di m-learning harus sesuai dengan gaya belajar masing-masing agar proses pembelajaran berjalan dengan efektif.

Dalam melakukan penelitian m-learning ini menggunakan model ADDIE dengan tahapan analisa, desain, pengembangan, implementasi dan evaluasi. model ADDIE dapat digunakan untuk mengembangkan instruksi dan konten literasi informasi[2]. Untuk mengevaluasi terhadap penerimaan teknologi m-learning ini dengan menggunakan model TAM (Technology Acceptance Model). Penerimaan teknologi $e$ learning sangat berpengaruh oleh kemudahan penggunaan dan niat untuk menggunakannya [1].
Adapun tujuan dari penelitian ini yaitu untuk mendesain dan membangun sistem m-learning di Polman Babel untuk mempermudah mahasiswa dalam melakukan proses pembelajaran dengan menggunakan perangkat mobile sehingga mereka dapat mengakses materi dan belajar sesuai dengan gaya belajar yang diinginkan.

\section{METODE PENELITIAN}

Metodologi yang digunakan dalam penelitian ini menggunakan model ADDIE dengan tahapan sebagai berikut:

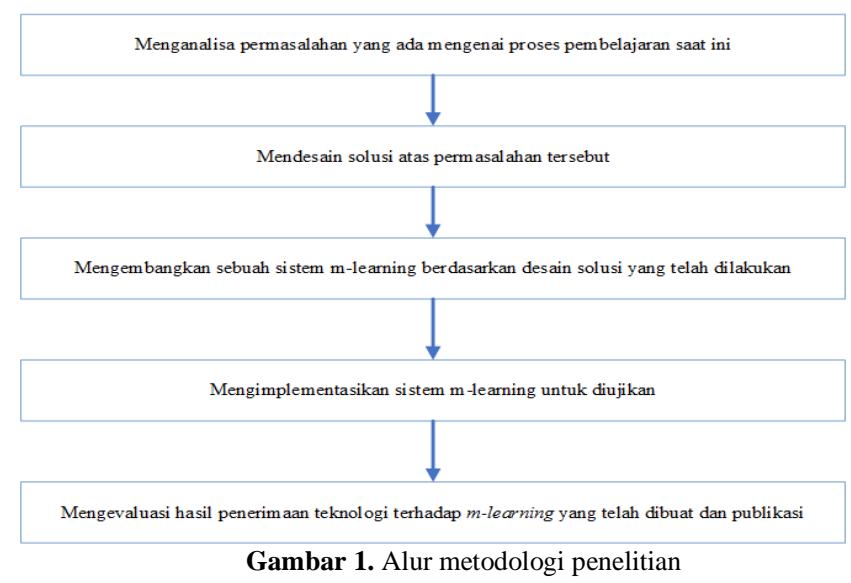

Adapun hasil evaluasi terhadap penerimaan teknologi m-learning dihubungkan dengan model TAM yang terdiri dari: persepsi kemudahan penggunaan (perceived ease of use), persepsi manfaat (perceived usefulness), dan minat perilaku untuk menggunakannya (behavior intention to use). Untuk melakukan pengukuran data menggunakan kuesioner dengan skala likert. Kuesioner tersebut disebarkan secara acak kepada mahasiswa Polman Babel dengan jumlah responden sebanyak 44 orang. Adapun perhitungan menggunakan skala likert dengan kriteria interpretasi skor berdasarkan interval sebagai berikut: 


\begin{tabular}{lc}
\multicolumn{2}{c}{ Tabel 1 Skala likert } \\
\hline \multicolumn{1}{c}{ Kriteria } & Prosenatse $(\%)$ \\
\hline Sangat Tidak Setuju & $0-19,99$ \\
Tidak Setuju & $20-39,99$ \\
Cukup & $40-59,99$ \\
Setuju & $60-79,99$ \\
Sangat Setuju & $80-100$ \\
\hline
\end{tabular}

\section{HASIL DAN PEMBAHASAN}

Adapun tahapan awal yang dilakukan yaitu menganalisa permasalahan proses pembelajaran saat ini dengan melakukan wawancara kepada mahasiswa di Polman Babel. Hasil wawancara dari beberapa mahasiswa diperoleh bahwa untuk mencari dan mendapatkan bahan materi perkuliahan secara online menggunakan $m$ learning belum ada. Setelah itu pada tahapan kedua yaitu mendesain solusi atas permasalahan dari hasil wawancara tersebut. Adapun desain untuk membangun m-learning sebagai berikut:

1. Mendesain arsitektur jaringan

Adapun desain arsitektur jaringan dapat dilihat pada Gambar 2.

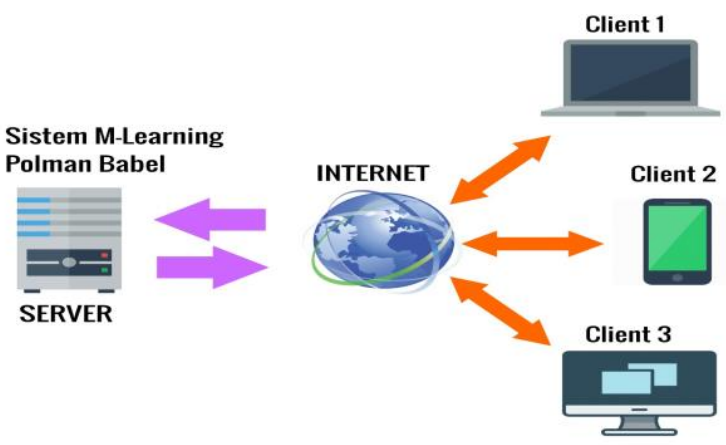

Gambar 2. Rancangan arsitektur jaringan

Untuk mengakses sistem m-learning diperlukan server untuk menyimpan dan memberikan layanan berupa data dan informasi pada klien melalui jaringan internet.

2. Mendesain kebutuhan fungsional sistem $m$ learning

Dalam mendesain kebutuhan fungsional yang akan dibangun pada sistem m-learning ini menggunakan use case diagram.

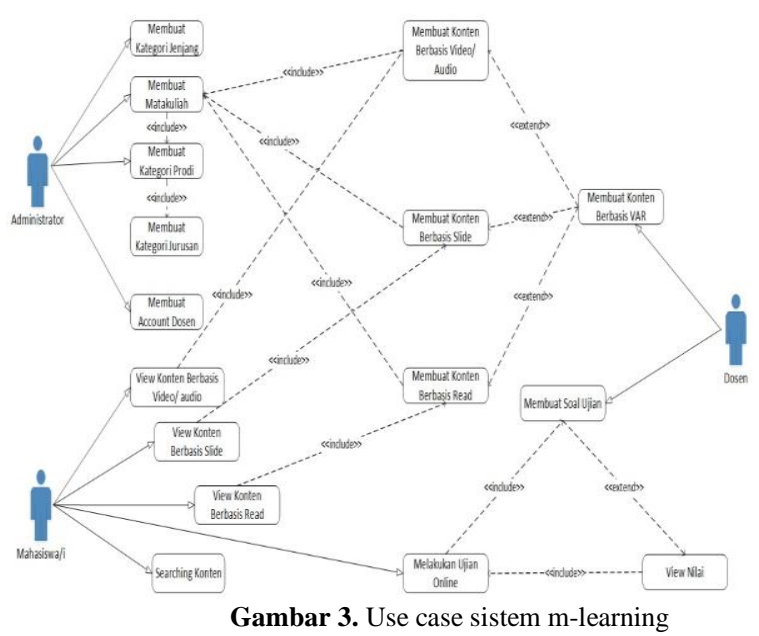

Ada tiga aktor dalam use case diatas dengan peran sebagai berikut:

1. Administrator: mengelola data dan informasi mengenai jenjang, jurusan. prodi dan matakuliah serta mengelola akun dosen di Polman Babel.

2. Dosen: mengelola konten VAR yang terdiri dari konten video, visual berupa slide, dan kontem read. Selain itu juga dosen dapat membuat soal ujian online pada materi yang diajarkan serta dapat melihat hasil ujian yang diberikan kepada mahasiswa secara realtime.

3. Mahasiswa: melihat materi pembelajaran baik berupa video, slide, maupun konten read. Mahasiswa juga dapat melakukan ujian online yang teredia di m-learning untuk menguji pemahaman materi yang telah dipelajari.

Tahapan ketiga yaitu melakukan pengembangan sistem m-learning dari mendesain database hingga melakukan coding. Adapun database yang digunakan menggunakan mysql serta menggunakan framework codeigniter dalam membangun sistem m-learning.

Tahapan selanjutnya yaitu melakukan implementasi terhadap sistem m-learning kepada mahasiswa dan dosen yang ada di Polman Babel. adapun gambaran sistem m-learning yang dibangun ada dua kategori pengaksesan yaitu:

1. Kategori website: sistem m-learning berbasis website ini digunakan oleh dosen untuk mengelola konten materi pembelajaran baik berbentuk video, slide dan lainnnya. Serta dosen dapat membuat soal ujian online sesuai dengan materi yang diajarkan. Adapun fitur-fiturnya sebagai berikut:

1.1. Fitur untuk mengelola konten read 


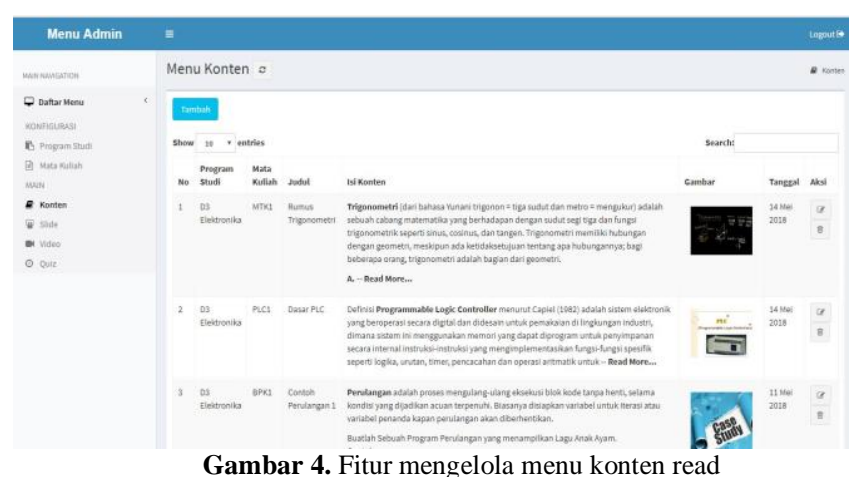

1.2. Fitur untuk mengelola konten video

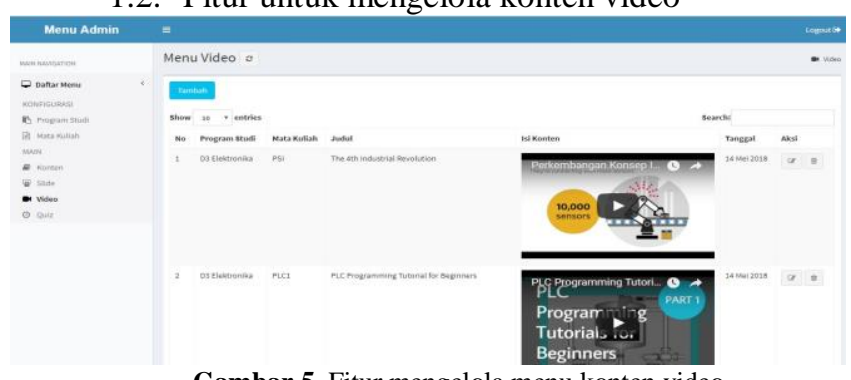

Gambar 5. Fitur mengelola menu konten video

1.3. Fitur untuk mengelola konten slide

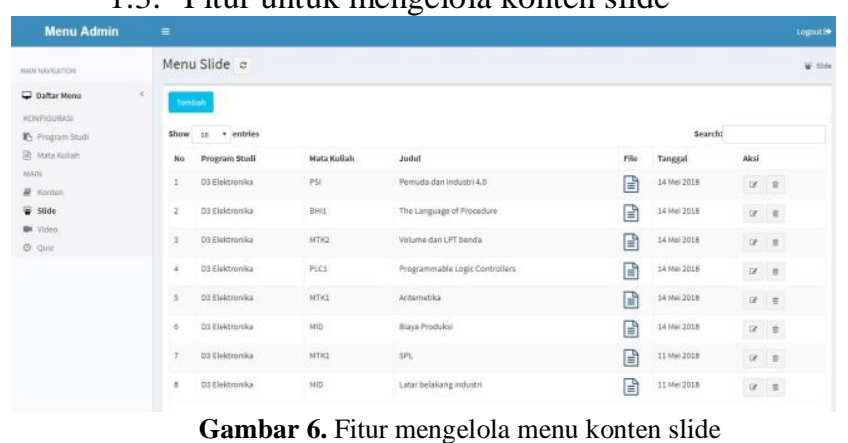

1.4. Fitur untuk mengelola soal ujian

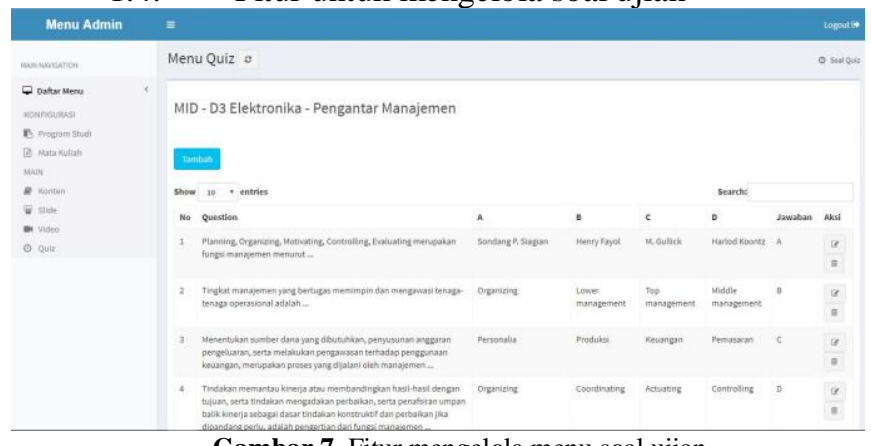

Gambar 7. Fitur mengelola menu soal ujian

2. Kategori Aplikasi mobile: sistem m-learning ini diakses oleh mahasiswa dengan menggunakan mobile. Adapun fitur-fiturnya terdiri dari konten, slide, video, ujian, web official dan sosial media.

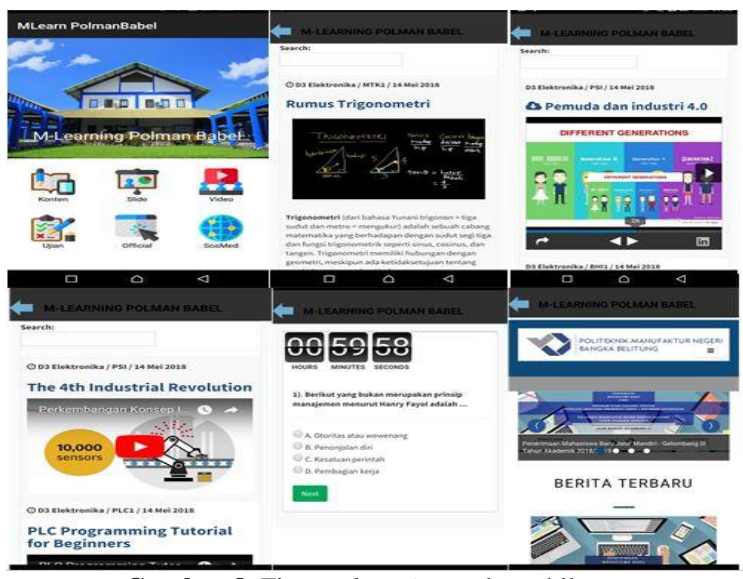

Gambar 8. Fitur m-learning pada mobile

Tahapan terakhir yaitu melakukan evaluasi pada sistem m-learning yang telah dibuat dengan menggunakan model TAM. Adapun hasil dari evaluasi menggunakan kuesioner dengan 44 responden sebagai berikut:

Tabel 2 Hasil gaya belajar yang disukai mahasiswa Polman

\begin{tabular}{cc}
\multicolumn{2}{c}{ Babel } \\
\hline Gaya Belajar & Prosenatse (\%) \\
\hline Visual & 84.09 \\
Audio & 6.82 \\
Read & 9.09 \\
\hline \multicolumn{2}{c}{ Sumber: Data primer yang diolah, Tahun 2018 }
\end{tabular}

Dari tabel diatas dapat dilihat bahwa $84 \%$ mahasiswa Polman Babel lebih menyukai gaya belajar visual dengan menggunakan bahan ajar berbentuk powerpoint. Selain itu juga untuk mengetahui penerimaan penggunaan teknologi $m$ learning di Polman Babel dihubungkan dengan model TAM dengan hasil sebagai berikut.

\begin{tabular}{lc}
\multicolumn{2}{c}{ Tabel 3 Hasil model TAM } \\
\hline \multicolumn{1}{c}{ Prespsi } & $\begin{array}{c}\text { Prosenatse } \\
(\%)\end{array}$ \\
\hline Kemudahan Penggunaan & 82.14 \\
Manfaat & 82.06 \\
Minat perilaku menggunakan & 80.62 \\
teknologi & \\
\hline \multicolumn{2}{c}{ Sumber: Data primer yang diolah, Tahun 2018 }
\end{tabular}

Dari tabel 2 diatas dapat dianalisa bahwa lebih dari $81 \%$ mahasiswa menerima penggunaan teknologi m-learning untuk diimplementasikan di Polman Babel baik dari presepsi kemudahaan penggunaan, manfaat dan minat perilaku dalam menggunakan teknologi tersebut. 


\section{SIMPULAN}

Dari hasil evaluasi diperoleh bahwa mahasiswa menerima penggunaan teknologi $m$ learning ini untuk diterapkan di Polman Babel karena kemudahaan penggunaanya, manfaat dan minat menggunakannya. M-learning ini sangat membantu mahasiswa untuk mendapatkan bahan ajar perkuliahan sesuai dengan gaya belajar yang disukai. Serta mahasiswa dapat mengakses mlearning secara efektif dan efisien dari sisi waktu. Untuk pengembangan penelitian selanjutnya mengenai desain m-learning ini dapat dikaitkan dengan model pembelajaran lainnya seperti collaborative learning, cooperative learning dan lain-lainya.

\section{REFERENSI}

[1] Hossein, M. (2015). Investigating user's perspectives on e-learning: An integartion of TAM and IS success model. Journal Computers in Human Behavior, 45, 359-374.

[2] Kimberly, M.(2014). Good IDEA: Instructional Design Model for Integrating Information Literacy. The Journal of Academic Librarianship, 40(3), 339-349.

[3] Ligi, B., \& Dr B. William, D. R. (2017). Mobile Learning In Higher Education. International Journal of Research - Granthaalayah, 5(4SE), 16.

[4] Manal, A., Wafaa, H. D., Reem, M. B., Mona, A., \& Malak ,S. (2015). The Impact of Learning Styles on Learner's Performance in E-Learning Environment. International Journal of Advance Computer Science and Application, 6(9), 24-31.

[5] Mostafa, A., Hatem, M. Elsherif., \& Khaled Shaalan. (2016). Investigating attitude towards the use of mobile learning in higher education. Journal Computers in Human Behavior, 56, 93102. 